\title{
ANALISIS PENGARUH KATALITIK KONVERTER TERHADAP PERFORMANSI DAN EMISI GAS BUANG MESIN DIESEL STASIONER SATU SILINDER MENGGUNAKAN BAHAN BAKAR BIODIESEL BIJI KEMIRI SUNAN
}

\author{
Andrey Stephan ${ }^{1}$, Tulus B. Sitorus ${ }^{2}$, Dian M. Nasution ${ }^{3}$, Alfian Hamsi ${ }^{4}$, Mahadi ${ }^{5}$ \\ 1.2,3,4,5 Departemen Teknik Mesin Fakultas Teknik Universitas Sumatera Utara \\ E-mail : andrey_si@yahoo.com
}

\begin{abstract}
ABSTRAK
Peningkatan jumlah penduduk secara eksponensial, keterbatasan sumber daya minyak menjadi sekian dari banyak hal yang mendorong manusia untuk melakukan penelitian dan pengembangan terhadap bahan bakar alternatif, salah satunya adalah penggunaan biji kemiri sunan untuk menghasilkan biodiesel. Penelitian ini bertujuan untuk menganalisa performansi mesin diesel TD-115 dengan menggunakan bahan bakar alternatif biodiesel biji kemiri sunan dan membandingkannya pada campuran tertentu serta penambahan katalitik konverter dengan tujuan mengurangi emisi gas buang. Daya aktual terbesar terjadi pada penggunaan solar putaran mesin $2800 \mathrm{rpm}$ yaitu sebesar $1.38854427 \mathrm{~kW}$ sedangkan daya terendah terjadi pada penggunaan bahan bakar biodiesel $20 \%$ pada putaran mesin $1800 \mathrm{rpm}$ yaitu sebesar 0.0361884 $\mathrm{kW}$. SFC maksimum pada bahan bakar solar + biodiesel biji kemiri sunan $20 \%$ beban $3.5 \mathrm{~kg}$ putaran $1800 \mathrm{rpm}$ yaitu sebesar $1161.24239 \mathrm{~g} / \mathrm{kW}$.jam, efisiensi termal maksimum pada bahan bakar solar dengan beban $4.5 \mathrm{~kg}$ dan putaran $2600 \mathrm{rpm}$ yakni sebesar 30.9212382\%, Opasitas terbesar pada penggunaan bahan bakar biodiesel biji kemiri sunan $15 \%$ dengan penambahan katalitik converter pada exhaust manifold yakni sebesar $42.1667 \%$. Kadar HC (hidro carbon) dan CO (carbon monoksida) mengalami penurunan saat menggunakan katalitik konverter.
\end{abstract}

Kata kunci: biodiesel kemiri sunan, performansi mesin diesel, katalitik converter

\section{PENDAHULUAN}

Harga minyak dunia yang bersumber dari fosil saat ini sangat tinggi, sementara itu cadangan minyak bumi di Indonesia semakin menipis, yang diperkirakan ketersediaannya sebanyak 86,9 milyar barel. Jumlah tersebut diperkirakan hanya akan dapat memenuhi kebutuhan energi dalam negeri selama 23 tahun ke depan. [1].

Oleh karena itu, dalam rangka mengurangi ketergantungan terhadap bahan bakar fosil, perlu segera mengambil langkah-langkah untuk mendapatkan sumber energi alternatif. Pengembangan bioenergi atau bahan bakar nabati sebagai sumber energi alternatif sangat strategis untuk mengatasi permasalahan tersebut

Selain itu meningkatnya jumlah kedaraan bermotor saat ini berimbas pada kualitas udara yang buruk di daerah perkotaan menuntut pabrikan motor berinovasi, salah satunya adalah katalitik konverter yang terdapat pada mobil keluaran saat ini[2].

\section{TINJAUAN PUSTAKA}

Biodiesel pertama kali diperkenalkan di Afrika selatan sebelum perang dunia II sebagai bahan bakar kenderaan berat. Biodiesel didefinisikan sebagai metil/etil ester yang diproduksi dari minyak tumbuhan atau hewan dan memenuhi kualitas untuk digunakan sebagai bahan bakar di dalam mesin diesel[3].

Konsep penggunaan minyak tumbuh-tumbuhan sebagai bahan pembuatan bahan bakar sudah dimulai pada tahun 1895 saat Dr. Rudolf Christian Karl Diesel (Jerman, 1858-1913) mengembangkan mesin kompresi pertama yang secara khusus dijalankan dengan minyak tumbuh-tumbuhan[4]. 


\section{Proses Produksi Biodiesel}

Secara garis besar proses pembentukan biodiesel dibagi menjadi dua tahapan, yaitu:

1. Tahap Esterifikasi

Esterifikasi adalah tahap konversi dari asam lemak bebas (FFA) menjadi ester. Esterifikasi mereaksikan asam lemak dengan alcohol. Reaksi ini merupakan reaksi kesetimbangan, jadi memerlukan katalis untuk mempercepat tercapainya keadaan setimbang. Katalis-katalis yang cocok adalah zat yang berkarakter asam kuat [5].

2. Tahap Transesterifikasi

Transesterifikasi adalah pertukaran alcohol dengan suatu ester untuk membentuk ester yang baru. Reaksi ini bersifat reversible dan berjalan lambat tanpa adanya katalis. Penggunaan alkohol atau mengambil alih salah satu produk adalah langkah untuk mendorong reaksi kearah kanan atau produk [5].

\section{Biodiesel Biji Kemiri Sunan}

Tanaman kemiri sunan (Reutealis trisperma (Blanco) Airy Shaw) sebagai tanaman penghasil minyak nabati. Tanaman ini telah tumbuh dengan baik di daerah Jawa Barat pada ketinggian 0-1000 m dpl, mampu berproduksi tinggi, berumur panjang dengan kanopi daun yang lebar dan perakaran dalam dengan produktivitas tanaman dan rendemen minyak yang tinggi tidak hanya potensial sebagai penghasil minyak nabati tetapi dapat juga digunakan sebagai tanaman konservasi. Bijinya yang beracun menjadikan tanaman ini tidak bersaing dengan pangan sebagai bahan baku pembuatan bahan bakar nabati[6].

\section{Katalitik Konverter}

Meningkatnya jumlah kedaraan bermotor saat ini berimbas pada kualitas udara yang buruk di daerah perkotaan menuntut pabrikan motor berinovasi, salah satunya adalah katalitik konverter yang terdapat pada mobil keluaran saat ini. Alat tersebut diperkenalkan ke publik pada tahun 1975 di Amerika Serikat, kebijakan tersebut sejalan dengan niat EPA dalam mengurangi intensitas pencemaran udara gas buang dikarenakan proses pembakaran kendaraan bermotor[7].

\section{Mesin Diesel}

Motor diesel disebut juga motor bakar atau mesin pembakaran dalam karena pengubahan tenaga kimia bahan bakar menjadi tenaga mekanik dilaksanakan di dalam mesin itu sendiri. Di dalam motor diesel terdapat torak yang mempergunakan beberapa silinder yang di dalamnya terdapat torak yang bergerak bolak-balik (translasi). Di dalam silinder itu terjadi pembakaran antara bahan bakar solar dengan oksigen yang berasal dari udara [8].

\section{Performansi Motor Bakar Daya Poros}

Semakin tinggi frekuensi putar motor makin tinggi daya yang diberikan hal ini disebabkan oleh semakin besarnya frekuensi semakin banyak langkah kerja yang dialami pada waktu yang sama[9]. Dengan demikian besar daya poros itu adalah :

$$
\mathrm{P}_{\mathrm{B}}=\frac{2 \pi .(\mathrm{n} . \mathrm{T})}{60} \ldots \ldots \ldots[\mathrm{i}]
$$

Dimana :

$\mathrm{P}_{\mathrm{B}}=\operatorname{daya}(\mathrm{W})$ 
$\mathrm{T}=\operatorname{torsi}(\mathrm{Nm})$

$\mathrm{n}=$ putaran mesin $(\mathrm{Rpm})$

\section{Konsumsi Bahan Bakar Spesifik (SFC)}

Parameter ini biasa dipakai sebagai ukuran ekonomi pemakaian bahan bakar yang terpakai per jam untuk setiaprdaxalbuda yang dihasilkan.

$$
\begin{aligned}
& S F C=\frac{f}{P_{B}} \ldots \ldots \ldots \ldots \ldots \ldots[9] \\
& m_{\mathrm{f}}=\frac{\rho_{\mathrm{f}} \cdot \mathrm{V}_{f} \cdot 10^{-6}}{t_{\mathrm{f}}} x 3600 \ldots \ldots[9]
\end{aligned}
$$

Dimana :

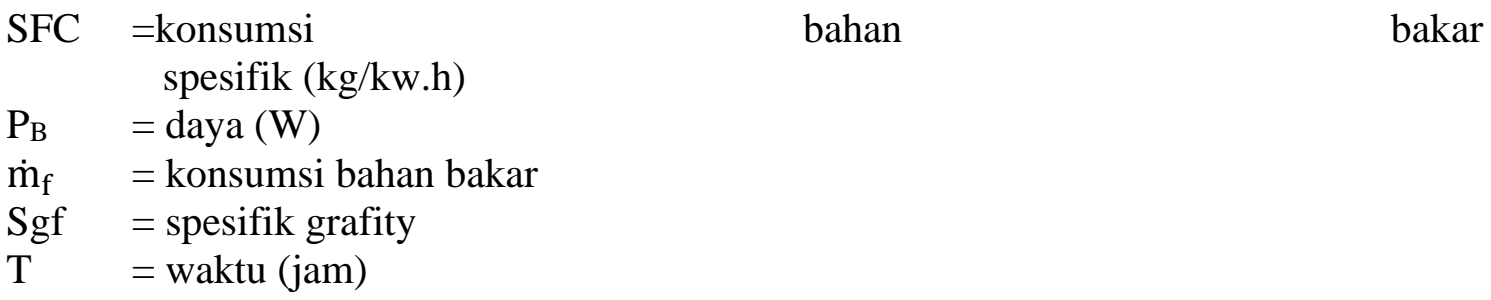

\section{Emisi Gas Buang}

Untuk mesin diesel emisi gas buang yang dilihat adalah opasitas dalam satuan $\%$. Pengukuran kadar HC (hidro karbon) dalam satuan ppm, dan $\mathrm{CO}$ dalam satuan \% Opasitas sendiri adalah tingkat ketebalan asap / gas buang dari mesin[10].

\section{METODOLOGI PENELITIAN}

\section{Metode pengumpulan data}

Data yang dipergunakan dalam pengujian ini meliputi :

a. Data primer, merupakan data yang diperoleh langsung dari pengukuran dan pembacaan pada unit instrumentasi serta alat ukur pada masing-masing pengujian.

b. Data sekunder, merupakan data yang diperoleh dari hasil penelitian bahan bakar solar dan biodiesel yang diperoleh dari pengujian bom kalori meter dan Pusat Penelitaian Kelapa Sawit (PPKS).

\section{Metode Pengolahan Data}

Data yang diperoleh dari data primer dan data sekunder diolah data dari perhitungan disajikan dalam bentuk tabulasi dan grafik

\section{Pengamatan dan Tahap Pengujian}

Parameter yang akan ditinjau dalam pengujian ini adalah :

1. Daya ( P )

2. Konsumsi bahan bakar spesifik ( sfc )

3. Efisiensi thermal $\left(\eta_{b}\right)$

4. Emisi gas buang

\section{Set-up Alat}

Adapun set-up pada pengujian performansi ini dapat dilihat pada gambar berikut ini : 


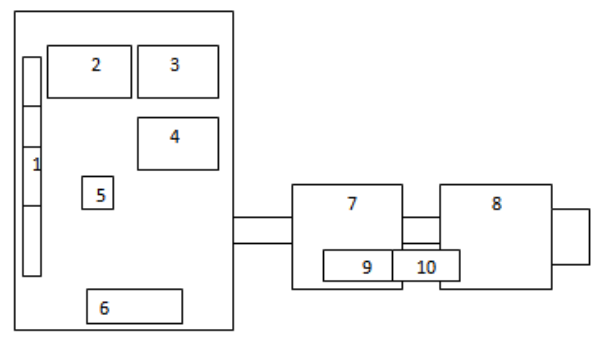

Gambar 3.1 Skema pengujian performansi

Keterangan gambar :

1. Flow Meter Bahan Bakar

2. Tacho meter (RPM)

3. Torsi meter $(\mathrm{Nm})$

4. Exhaust Temperature $\left({ }^{\circ} \mathrm{C}\right)$

5. Tombol ON/OFF

6. Manometer $\left(\mathrm{mmH}_{2} \mathrm{O}\right)$

7. Mesin TD-111

8. Dynamometer

9. Exhaust Muffler

10. Katalitik Konverter.

\section{Prosedur Pengujian performansi}

Pengujian dapat dilakukan dengan dengan beberapa langkah-langkah. pertamatama kalibrasi Instrumentasi mesin diesel sebelum digunakan, kemudian mesin dioperasikan dengan cara memutar poros engkol mesin, kemudian mesin dipanaskan selama 10 menit. Selanjutnya putaran mesin diatur pada 1800 RPM menggunakan tuas kecepatan dan melihat data analog pada instrument. Kemudian ditentukan konsumsi bahan bakar yang akan diuji. Selanjutnya diukur waktu yang diperlukan untuk menghabiskan $8 \mathrm{ml}$ bahan bakar. Pengujian dilakukan dengan menggunakan variasi putaran yang berbeda (1800 RPM, 2000 RPM, 2200 RPM, 2400 RPM, 2600 RPM, 2800 RPM)

\section{Prosedur Pengujian emisi gas buang}

Prosedur pengujian emisi gas buang dilakukan dengan menekan tombol power yang ada di belakang alat. kemudian kita tunggu sampai alat selesai melakukan proses pemanasan (warming up). Selanjutnya tombol display ditekan sampai di layar LED muncul tanda "\%". Tombol "HOLD" untuk mengubah alat menjadi status "Peak Hold". Kemudian kita pasang probe tester ke ujung knalpot mesin dan selanjutnya kita naikkan putaran mesin secara cepat pada putaran mesin yang telah dibatasi. Pengujian dilakukan dengan variasi bahan bakar yang berbeda. 


\section{ANALISA \& PEMBAHASAN \\ Daya}

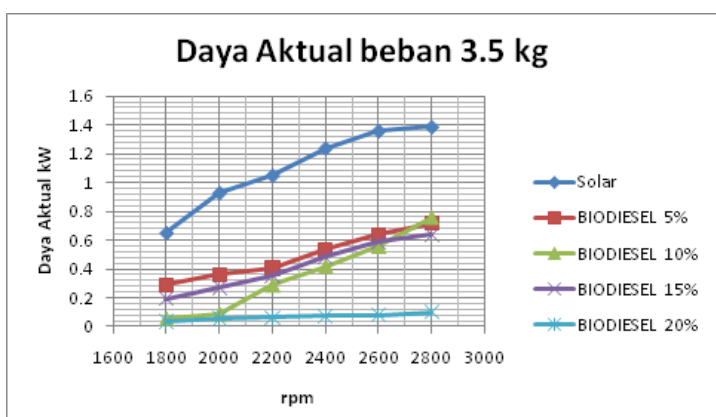

Gambar 2 Grafik daya vs putaran pada beban $3.5 \mathrm{~kg}$

Seperti terlihat pada gambar 2 diatas, pada pembebanan $3.5 \mathrm{~kg}$ daya aktual terbesar terjadi pada penggunaan solar putaran mesin $2800 \mathrm{rpm}$ yaitu sebesar $1.38854427 \mathrm{~kW}$ sedangkan daya terendah terjadi pada penggunaan bahan bakar biodiesel $20 \%$ pada putaran mesin $1800 \mathrm{rpm}$ yaitu sebesar $0.0361884 \mathrm{~kW}$. Dari sini dapat dilihat bahwa daya berbanding lurus dengan putaran.

Daya Aktual beban $4.5 \mathrm{~kg}$

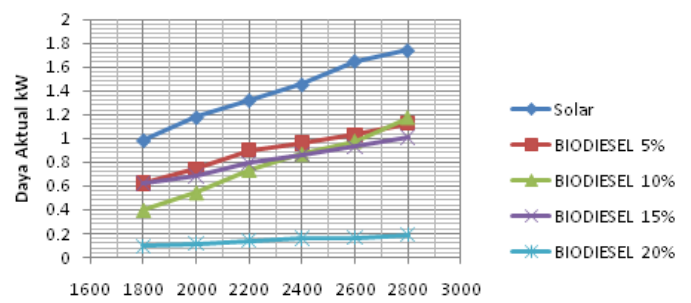

$\mathrm{rpm}$

Gambar 3 Grafik daya vs putaran pada beban $4.5 \mathrm{~kg}$

Berdasarkan gambar 3 diatas, dibandingkan saat menggunakan solar murni daya mesin cenderung turun pada saat penggunaan biodiesel. Dimana daya terendah terjadi pada penggunaan biodiesel $20 \%$. Pada pembebanan $4.5 \mathrm{~kg}$ daya aktual terbesar terjadi pada penggunaan solar pada putaran mesin $2800 \mathrm{rpm}$ yaitu sebesar $1.74080592 \mathrm{~kW}$ sedangkan daya aktual terkecil terjadi pada penggunaan biodiesel $20 \%$ putaran mesin $1800 \mathrm{rpm}$ yaitu sebesar $0.09563328 \mathrm{~kW}$.

\section{Konsumsi Bahan Bakar Spesifik (SFC)}

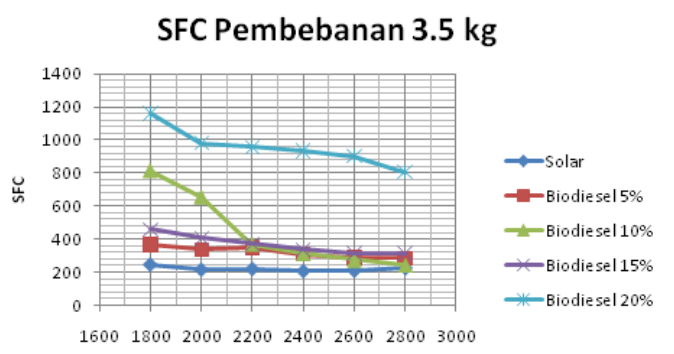

$\mathrm{rpm}$

Gambar 4 Grafik SFC vs putaran pada beban $3.5 \mathrm{~kg}$ 
Pada pemebebanan $3.5 \mathrm{~kg}$ SFC tertinggi terjadi pada penggunaan biodiesel $20 \%$ putaran mesin $1800 \mathrm{rpm}$ yaitu sebesar $1161.24239 \mathrm{gr} / \mathrm{kWh}$ dan SFC terendah terjadi pada penggunaan bahan bakar solar putaran mesin $2400 \mathrm{rpm}$ yaitu sebesar 205.274179 $\mathrm{gr} / \mathrm{kWh}$.

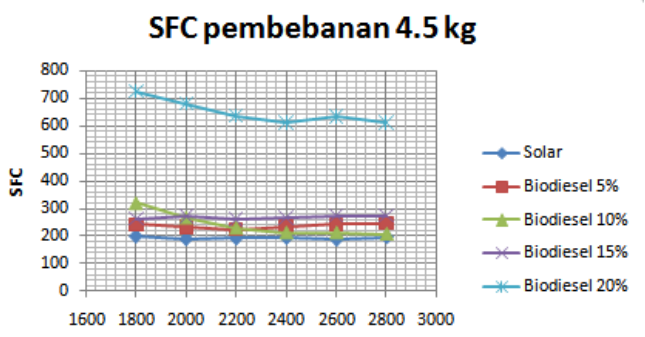

$\mathrm{rpm}$

Gambar 5 Grafik SFC vs putaran pada beban $4.5 \mathrm{~kg}$

Pada pembebanan $4.5 \mathrm{~kg}$ SFC tertinggi terjadi pada penggunaan biodiesel $20 \%$ putaran mesin $1800 \mathrm{rpm}$ yaitu sebesar $724.663118 \mathrm{gr} / \mathrm{kWh}$ dan SFC terendah terjadi pada penggunaan bahan bakar solar pada putaran mesin 2600 yaitu sebesar 187.960105 $\mathrm{gr} / \mathrm{kWh}$

SFC terbesar terjadi pada biodiesel $20 \%$ putaran terendah karena pada putaran ini memiliki nilai $\mathrm{mf}$ terendah. Selain itu hal ini dipengaruhi oleh nilai kalor bahan bakar yang paling kecil dibanding semua bahan bakar yang tersedia. Nilai kalor yang rendah mengakibatkan konsumsi bahan bakar yang terjadi setiap jamnya semakin tinggi persatuan daya yang dibangkitkannya.

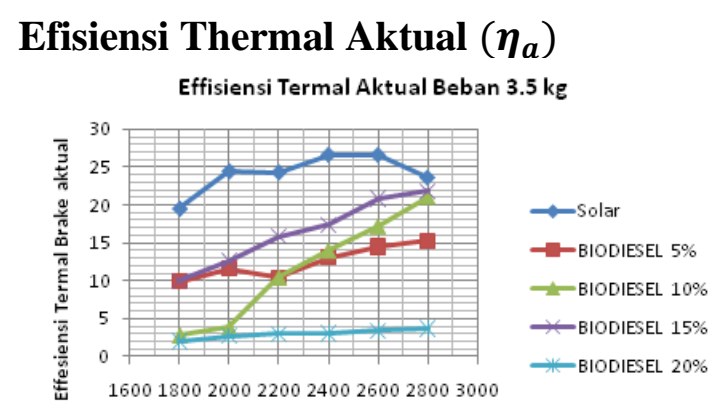

rpm

Gambar 6 Grafik Efisiensi thermal vs putaran pada beban $3.5 \mathrm{~kg}$

Pada pembebanan $3.5 \mathrm{~kg}$ effisiensi termal aktual tertinggi terjadi pada penggunaan solar putaran mesin $2600 \mathrm{rpm}$ sebesar $26.5729123 \%$ sedangkan effisiensi termal aktual terendah terjadi pada penggunaan biodiesel $20 \%$ putaran mesin $1800 \mathrm{rpm}$ yaitu sebesar $1.99188773 \%$

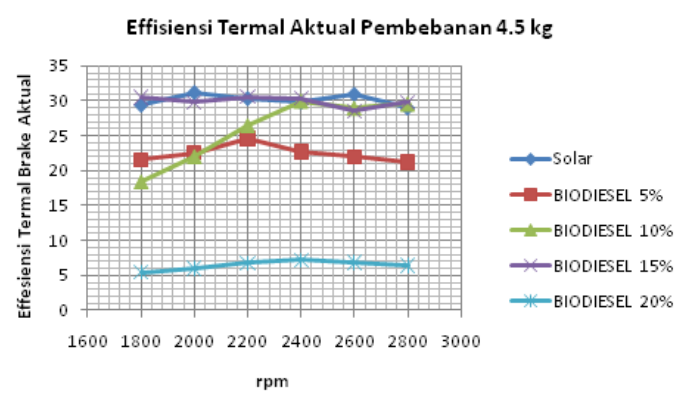

Gambar 7 Grafik efisiensi thermal vs putaran pada beban $4.5 \mathrm{~kg}$ 
Berdasarkan gambar 7 diatas, Pada pembebanan $4.5 \mathrm{~kg}$ effisiensi termal aktual tertinggi terjadi pada penggunaan solar putaran mesin $2600 \mathrm{rpm}$ yaitu sebesar $30.9212382 \%$ sedangkan effisiensi termal aktual terendah mesin terjadi pada penggunaan biodiesel $20 \%$ putaran $1800 \mathrm{rpm}$ yaitu sebesar $5.48026455 \%$

Effisiensi cenderung tinggi pada penggunaan bahan bakar solar pada putaran mesin yang tinggi, hal tersebut dikarenakan nilai kalor bahan bakar yang tinggi dari solar dibandingkan biodiesel, sedangkan effesiensi terendah terjadi pada penggunaan biodiesel 20\% karena memiliki nilai kalor terkecil dari semuanya.

\section{Emisi gas buang}

Tabel 1 Hasil uji emisi gas (opasitas) buang dengan menggunakan katalitik konverter beban $3.5 \mathrm{~kg}$

\begin{tabular}{|l|r|}
\hline Bahan Bakar & Average (\%) \\
\hline Solar & 23.06667 \\
\hline Biodiesel 5\% & 26.7 \\
\hline Biodiesel 10\% & 40.93333 \\
\hline Biodiesel 15\% & 35.3 \\
\hline Biodiesel 20\% & 31.23333 \\
\hline
\end{tabular}

Tabel 2 Hasil uji emisi gas buang (opasitas) dengan menggunakan katalitik konverter beban $4.5 \mathrm{~kg}$

\begin{tabular}{|l|r|}
\hline Bahan Bakar & $\begin{array}{l}\text { Average } \\
(\%)\end{array}$ \\
\hline Solar & 21.93333 \\
\hline Biodiesel 5\% & 32.7667 \\
\hline Biodiesel 10\% & 33.4667 \\
\hline Biodiesel 15\% & 42.1667 \\
\hline Biodiesel 20\% & 42 \\
\hline
\end{tabular}

Tabel 3 Hasil uji emisi gas buang (CO) dengan menggunakan katalitik konverter beban $3.5 \mathrm{~kg}$

\begin{tabular}{|l|r|}
\hline Bahan Bakar & Mean (\%) \\
\hline Solar & 0.04333 \\
\hline Biodiesel 5\% & 0.03667 \\
\hline Biodiesel 10\% & 0.02667 \\
\hline Biodiesel 15\% & 0.033333 \\
\hline Biodiesel 20\% & 0.03667 \\
\hline
\end{tabular}

Tabel 4 Hasil uji emisi gas buang (CO) dengan menggunakan katalitik konverter beban $4.5 \mathrm{~kg}$

\begin{tabular}{|l|r|}
\hline Bahan Bakar & Mean (\%) \\
\hline Solar & 0.04667 \\
\hline Biodiesel 5\% & 0.03667 \\
\hline Biodiesel 10\% & 0.03 \\
\hline Biodiesel 15\% & 0.04 \\
\hline Biodiesel 20\% & 0.03667 \\
\hline
\end{tabular}

Tabel 5 Hasil uji emisi gas buang (HC) dengan menggunakan katalitik konverter beban $3.5 \mathrm{~kg}$ 


\begin{tabular}{|l|r|}
\hline Bahan Bakar & Mean (ppm) \\
\hline Solar & 20 \\
\hline Biodiesel 5\% & 22.3333 \\
\hline Biodiesel 10\% & 30.3333 \\
\hline Biodiesel 15\% & 26.6667 \\
\hline Biodiesel 20\% & 24.3333 \\
\hline
\end{tabular}

Tabel 5 Hasil uji emisi gas buang (HC) dengan menggunakan katalitik konverter beban $3.5 \mathrm{~kg}$

\begin{tabular}{|l|r|}
\hline Bahan Bakar & Mean(ppm) \\
\hline Solar & 24.3333 \\
\hline Biodiesel 5\% & 23.6667 \\
\hline Biodiesel 10\% & 19.3333 \\
\hline Biodiesel 15\% & 26 \\
\hline Biodiesel 20\% & 28.6667 \\
\hline
\end{tabular}

Nilai Opasitas terbesar terjadi pada penggunaan katalitik converter pada pembebanan $4.5 \mathrm{~kg}$ biodiesel $15 \%$ yaitu sebesar $42.1667 \%$ sedangkan Opasitas terendah terjadi pada pembebanan $4.5 \mathrm{~kg}$ biodiesel 5\% tampa menggunakan katalitik konveter yaitu sebesar $17.4667 \%$

Nilai CO terebesar terjadi pada saat tidak menggunakan katalitik converter yaitu pada pembebanan $3.5 \mathrm{~kg}$ biodiesel $15 \%$ dan beban $4.5 \mathrm{~kg}$ biodiesel $20 \%$ yaitu sebesar $0.063333 \%$ sedangkan Nilai CO terendah terjadi pada saat penggunaan katalitik converter bahan bakar biodiesel $10 \%$ yaitu sebesar $0.026667 \%$

Nilai HC terbesar terjadi pada saat tidak menggunakan katalitik converter pada pembebanan $3.5 \mathrm{~kg}$ bahan bakar biodiesel $5 \%$ yaitu sebesar 40 ppm sedangkan nilai HC terendah terjadi pada penggunaan katalitik converter pada pembebanan 4.5 biodiesel $10 \%$ yaitu sebesar $19.333 \mathrm{ppm}$

Nilai opasitas yang cenderung meningkat pada saat menggunakan katalitik converter karena adanya reaksi oxidization catalyst. Proses ini mengurangi hidrokarbon yang tidak terbakar di ruang bakar dan $\mathrm{CO}$ dengan membakarnya (oxidizing) melalui katalis platinum dan palladium. Katalis ini membantu reaksi $\mathrm{CO}$ dan $\mathrm{HC}$ dengan oksigen yang ada di dalam gas buang. Reaksinya sebagai berikut; ${ }_{2} \mathrm{CO}+\mathrm{O}_{2}=>2 \mathrm{CO}_{2}$. Selain mengubah $\mathrm{CO}$ menjadi $\mathrm{CO}_{2}$ proses ini mengubah $\mathrm{HC}$ dan $\mathrm{CO}$ ke dalam bentuk uap air sehingga meningkatkan nilai opasitas (kekabutan).

\section{KESIMPULAN}

1. Semakin besar nilai laju aliran bahan bakar, semakin besar pula konsumsi bahan Bakar. SFC minimum pada bahan bakar Solar beban $4.5 \mathrm{~kg}$ putaran $2600 \mathrm{rpm}$ yaitu sebesar $187.960105 \mathrm{~g} / \mathrm{kW}$.jam. Sedangkan SFC Maksimum pada bahan bakar Solar + Biodiesel biji kemiri sunan $20 \%$ beban $3.5 \mathrm{~kg}$ putaran $1800 \mathrm{rpm}$ yaitu sebesar 1161.24239 $\mathrm{g} / \mathrm{kW}$.jam. Besar SFC sangat dipengaruhi oleh besar kecil nilai laju aliran bahan bakar. Semakin besar nilai laju aliran bahan bakar, semakin besar pula konsumsi bahan bakar spesifiknya, demikian sebaliknya

2. Pada pembebanan $3.5 \mathrm{~kg}$ daya aktual terbesar terjadi pada penggunaan solar putaran mesin $2800 \mathrm{rpm}$ yaitu sebesar $1.38854427 \mathrm{~kW}$ sedangkan daya terendah terjadi pada 
penggunaan bahan bakar biodiesel $20 \%$ pada putaran mesin $1800 \mathrm{rpm}$ yaitu sebesar $0.0361884 \mathrm{~kW}$. Pada pembebanan $4.5 \mathrm{~kg}$ daya aktual terbesar terjadi pada penggunaan solar pada putaran mesin $2800 \mathrm{rpm}$ yaitu sebesar $1.74080592 \mathrm{~kW}$ sedangkan daya aktual terkecil terjadi pada penggunaan biodiesel $20 \%$ putaran mesin $1800 \mathrm{rpm}$ yaitu sebesar $0.09563328 \mathrm{~kW}$. Besarnya daya ditentukan oleh besarnya nilai kalor bahan bakar dan besarnya putaran. Semakin tinggi nilai kalor maka nilai daya yang dapat dibangkitkan akan semakin tinggi begitu pula sebaliknya, demikian pula dengan putaran semakin tinggi putaran mesin maka nilai daya akan semakin besar.

3. Efisiensi termal minimun pada campuran bahan bakar solar + biodiesel biji kemiri sunan $20 \%$ dengan beban $3.5 \mathrm{~kg}$ dan putaran 1800 rpm yakni sebesar 1.99188773\%. Nilai Efisiensi Thermal maximum pada bahan bakar solar dengan beban $4.5 \mathrm{~kg}$ dan putaran $2600 \mathrm{rpm}$ yakni sebesar $30.9212382 \%$

\section{DAFTAR PUSTAKA}

[1] Kementrian ESDM. 2011. Handbook of Energy and economy Statistic Indonesia, Jakarta : Indonesia

[2] http://Jenis-jenis katalitik konverter co.id/pemakaian/fungsi/ syarat-pemakaiandan-hasil-penggunaan.

[3] J Arjuna et al 2018 IOP Conf. Ser.: Mater. Sci. Eng. 309012088

[3] Irvan et al 2017 IOP Conf. Ser.: Mater. Sci. Eng. 206012028

[4] Kartika , I. A., M. Yani, dan D. Hermawan. 2011. Transesterifikasi in situ biji jarak pagar: Pengaruh jenis pereaksi, kecepatan pengadukan dan suhu reaksi terhadap rendemen dan kualitas biodiesel. Teknologi Industri Pertanian 21(1): 24-33

[5] Pranowo, D. 2009. Bunga Rampai Kemiri Sunan Penghasil Biodiesel, Solusi Masalah Energi Masa Depan. Teknologi Perbenihan. Balai Penelitian Tanaman Rempah dan Aneka Tanaman industri.

[6] Herman, M. dan D. Pranowo.2011. Karateristik buah dan minyak kemiri (Reutalis trisperma (Blanco) Airy Shaw) populasi Majalengka dan Garut. Buletin Riset Tanaman Rempah dan Industri 2(1): 21-28

[7] http://Jenis-jenis katalitik konverterco.id/pemakaian/fungsi/ syarat-pemakaiandan-hasil-penggunaan.

[8] Kubota S dan Takigawa. 2001. Diesel engine Performance. Prentice Hall, New Jersey.

[9] Pulkrabek, Willard W. Engineering Fundamentals Of The Internal Combustion Engine. New Jersey : Prentice Hall.

[10] F. Ariani et al 2017 IOP Conf. Ser.: Mater. Sci. Eng. 277 012045F. Ariani et al 2017 IOP Conf. Ser.: Mater. Sci. Eng. 277012045 